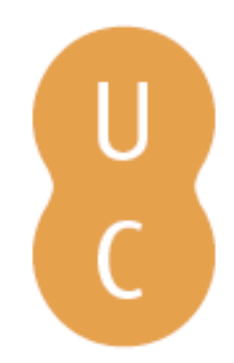

\title{
nommalina
}

\section{Quantificação de focos de calor nas mesorregiões do Estado da Bahia - Brasil entre os anos de 2010 e 2013}

\author{
Autor(es): $\quad$ Arnaut, Adriana Andrade; Santos, Antonio José Prado Martins \\ Publicado por: Imprensa da Universidade de Coimbra \\ URL \\ persistente: URI:http://hdl.handle.net/10316.2/37067 \\ DOI: $\quad$ DOI:http://dx.doi.org/10.14195/978-989-26-0983-6_14 \\ Accessed : $\quad$ 26-Apr-2023 14:54:55
}

A navegação consulta e descarregamento dos títulos inseridos nas Bibliotecas Digitais UC Digitalis, UC Pombalina e UC Impactum, pressupõem a aceitação plena e sem reservas dos Termos e Condições de Uso destas Bibliotecas Digitais, disponíveis em https://digitalis.uc.pt/pt-pt/termos.

Conforme exposto nos referidos Termos e Condições de Uso, o descarregamento de títulos de acesso restrito requer uma licença válida de autorização devendo o utilizador aceder ao(s) documento(s) a partir de um endereço de IP da instituição detentora da supramencionada licença.

Ao utilizador é apenas permitido o descarregamento para uso pessoal, pelo que o emprego do(s) título(s) descarregado(s) para outro fim, designadamente comercial, carece de autorização do respetivo autor ou editor da obra.

Na medida em que todas as obras da UC Digitalis se encontram protegidas pelo Código do Direito de Autor e Direitos Conexos e demais legislação aplicável, toda a cópia, parcial ou total, deste documento, nos casos em que é legalmente admitida, deverá conter ou fazer-se acompanhar por este aviso.

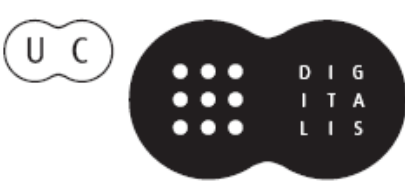




\section{$\forall$ \\ TAS DAS I JORNADAS LUSÓFONAS DE CIÊNCIAS E TECNOLOGIAS DE INFORMAÇÃO GEOGRÁFICA}

Editores

José Gomes dos Santos

Cidália Fonte

Rui Ferreira de Figueiredo

Alberto Cardoso

Gil Gonçalves

José Paulo Almeida

Sara Baptista 


\title{
ARTIGO 14
}

\section{QUANTIFICAÇÃo DE FOCOS DE CALOR NAS MESORREGIÕES DO ESTADO DA BAHIA - BRASIL ENTRE OS ANOS DE 2010 E 2013}

\author{
ARNAUT, Adriana Andrade ${ }^{1}$ \& SANTOS, Antonio José Prado Martins ${ }^{2}$
}

Instituto Federal de Educação, Ciência e Tecnologia Baiano - Campus Catu (Brasil); Rua Barão de Camaçari, 118, Centro, 48110-000, Catu, Bahia, Brasil; Tel: +55 71 36417901;

email: ${ }^{1}$ adriana.arnaut@catu.ifbaiano.edu.br; ${ }^{2}$ antonio.prado@catu.ifbaiano.edu.br

\section{RESUMO}

O número de queimadas no território brasileiro vem crescendo nos últimos anos, podendo ser oriundas de causas naturais ou pela ação humana, principalmente nas regiões de fortes atividades agrícolas cuja cultura de queimadas ainda está associada à adubação do solo e, consequentemente, à melhora da qualidade da lavoura. Esta prática nem sempre permite o controle do fogo, podendo assim, causar grandes incêndios. Atualmente, a verificação de ocorrência de focos de calor é possível pela análise de imagens de satélite a qual possibilita uma constante verificação na relação espaço-temporal da superfície terrestre. Este artigo mostra a contagem dos pontos de focos de calor a partir de shapefiles gerados do resultado do imageamento do satélite NOAA-15 (manhã e noite), entre os anos de 2010 e 2013, disponíveis no Programa de Monitoramento de Queimadas e Incêndios do sítio do Instituto Nacional de Pesquisas Espaciais (INPE), buscando identificar e comparar os quantitativos dos focos de calor para as mesorregiões do estado da Bahia, com o uso da tecnologia de Sistema de Informação Geográfica (SIG). 


\title{
PALAVRAS-CHAVE
}

Bahia, Focos de calor, Mesorregiões, Quantum GIS.

\author{
QUANTIFICATION OF HOTSPOTS IN THE MESOREGIONS OF \\ THE STATE OF BAHIA - BRAZIL BETWEEN 2010 AND 2013
}

\begin{abstract}
The number of burned in Brazilian territory is growing in last years, originated from natural causes or for human action, mainly in regions of agricultural activities that culture of burned is associated to soil fertilization yet and, consequently, improvement of quality of farming. This manner not always allow the control of fire, causing large fire. Nowadays, the inspection of occurrence of hotspots is possible through of satellite image that possibility an inspection constant in relation to spatiotemporal of land surface. This article shows the search of hotspot points through of shapefiles from the result of imaging NOAA-15 satellite (morning and night), between 2010 and 2013 years, available in Monitoring Program of Fires from the website of National Institute for Space Research (INPE), looking for identify and compare the quantities of hotspots to mesoregions state of Bahia, with the use of technology by Geographic Information System (GIS).
\end{abstract}

\section{KEYWORDS}

Bahia, Hotspots, Mesoregions, Quantum GIS.

\section{INTRODUÇÃo}

Com a evolução das geotecnologias a atividade de geoprocessamento vem influenciando crescentemente as pesquisas nas áreas de cartografia, análise de recursos naturais, comunicação, transporte, energia, planejamento urbano e regional, dentre outras. A informação geográfica constitui-se na "peça chave" deste desenvolvimento tecnológico, pois é a partir dela que são representados e caracterizados os fenômenos.

Segundo Câmara e Medeiros (1998, 1), “[...] Geoprocessamento denota a disciplina do conhecimento que utiliza técnicas matemáticas e computacionais para o tratamento da informação geográfica.”

Dentre as tecnologias do geoprocessamento, encontra-se o Sistema de Informação Geográfica (SIG). De acordo com Burrough e McDonnell 
(1998, 11, tradução livre dos autores) o SIG é “um poderoso conjunto de ferramentas para coletar, armazenar, recuperar, transformar e exibir dados espaciais do mundo real para determinados propósitos.” Assim, torna-se um instrumento importante para auxílio à tomada de decisões em questões complexas de planejamento, gerenciamento e operações. Para Matias (2001, 277), "o uso da tecnologia SIG instaura-se nas últimas décadas como um importante instrumento de aquisição, produção de análises e representação de informações sobre o espaço geográfico.”

Este trabalho visa representar e quantificar os focos de calor registrados no estado da Bahia, bem como avaliar sua espacialização, entre os anos de 2010 e 2013, identificando quais das mesorregiões do referido estado apresentaram maior nível de comprometimento quanto à ocorrência de incêndio na vegetação.

Utilizando a ferramenta de SIG livre Quantum GIS (QGIS), elaborou-se mapas os quais apresentam a contagem dos focos de queimadas no estado da Bahia, entre os anos de 2010 a 2013, abordando assim a visualização espacial e temporal deste fenômeno. Além disto, buscou-se apresentar a contagem dos referidos focos em cada mesorregião desse estado, para o mesmo período citado, relacionando-a com a precipitação média anual.

\section{ApresentaÇÃo do TEMA}

Com o aumento da ocupação do território brasileiro, o número de queimadas vem crescendo nos últimos anos, podendo ser oriundas de causas naturais ou pela ação humana. Nas regiões onde existe o manejo da agropecuária, as práticas de queimadas aparecem com a finalidade de preparar o solo. Mas nem sempre os responsáveis por tais práticas conseguem controlar o alastramento do fogo, podendo acarretar incêndio.

Atualmente, o uso de imagens de satélite de sensoriamento remoto aparece como uma forma de identificar focos de queimadas. O satélite NOAA-15 (National Oceanic Atmospheric Administration) possui o sensor AVHRR (Advanced Very High Resolution Radiomete) que opera em cinco canais (1 - vermelho, 2 - infravermelho próximo, 3 - infravermelho médio, 4 - infravermelho termal e 5 - infravermelho termal) com uma resolução 
espacial de 1,1 km, e é capaz de fornecer, pelo menos, duas imagens por dia (manhã e noite) da mesma área, sem custo. Entre as suas aplicações, pode-se citar: análise da cobertura vegetal, monitoramento de queimadas, meteorologia, mapeamento de seca, dentre outras. Os mapas de focos de calor fornecem uma visualização dos possíveis pontos de queimadas, numa temperatura acima de $47^{\circ} \mathrm{C}$, identificados pelo satélite NOAA.

Florenzano $(2007,59)$ afirma que "a importância da detecção e do monitoramento de queimadas transcende ao problema do desmatamento em si, trazendo contribuições também aos estudos de modificações do clima, incluindo: efeito estufa, chuva ácida, influência dos aerossóis na visibilidade, balanço de energia, formação de nuvens e precipitação. Fica evidente, portanto, que o excesso de áreas queimadas tem implicações ecológicas, climáticas e ambientais diversas."

\section{METODOLOGIA UTILIZADA}

A Bahia é um estado brasileiro localizado na região nordeste do país, mais precisamente no sul dessa região e suas coordenadas geográficas

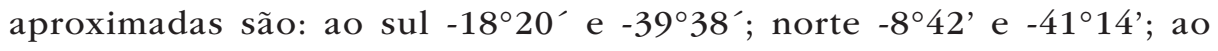
oriente; $-11^{\circ} 26^{\prime}$ e $-37^{\circ} 18^{\prime}$; e a ocidente, $-12^{\circ} 34^{\prime}$ e $-46^{\circ} 13^{\prime}$. Essa unidade da federação limita-se com os estados de Alagoas, Sergipe, Pernambuco, além do Piauí ao norte, Minas Gerais e Espírito Santo ao sul, Goiás e Tocantins a oeste e ao leste com o oceano Atlântico, ocupando uma área de 564733,177 km2. A Figura 1 apresenta o mapa de localização do estado da Bahia. Segundo o Censo Demográfico do Instituto Brasileiro de Geografia e Estatística (IBGE) realizado em 2010, possui população de 14016906 habitantes. No interior do território existem diferentes tipos de relevos (dunas, planícies e manguezais no litoral, ao sudeste aparecem os planaltos e no vale do rio São Francisco as depressões), climas (predominantemente o tropical, além do semi-árido está presente no sertão), vegetações (caatinga que ocupa a maior parte, floresta tropical úmida e cerrado) e hidrografia (932 km de costa tendo como principal rio o São Francisco). O IBGE divide o estado da Bahia em 7 (sete) mesorregiões, ou seja, reúnem municípios de uma mesma área geográfica com similaridades 
econômicas e sociais. As mesorregiões são: Centro Norte Baiano, Centro Sul Baiano, Extremo Oeste Baiano, Metropolitana de Salvador, Nordeste Baiano, Sul Baiano e Vale São-Franciscano da Bahia.
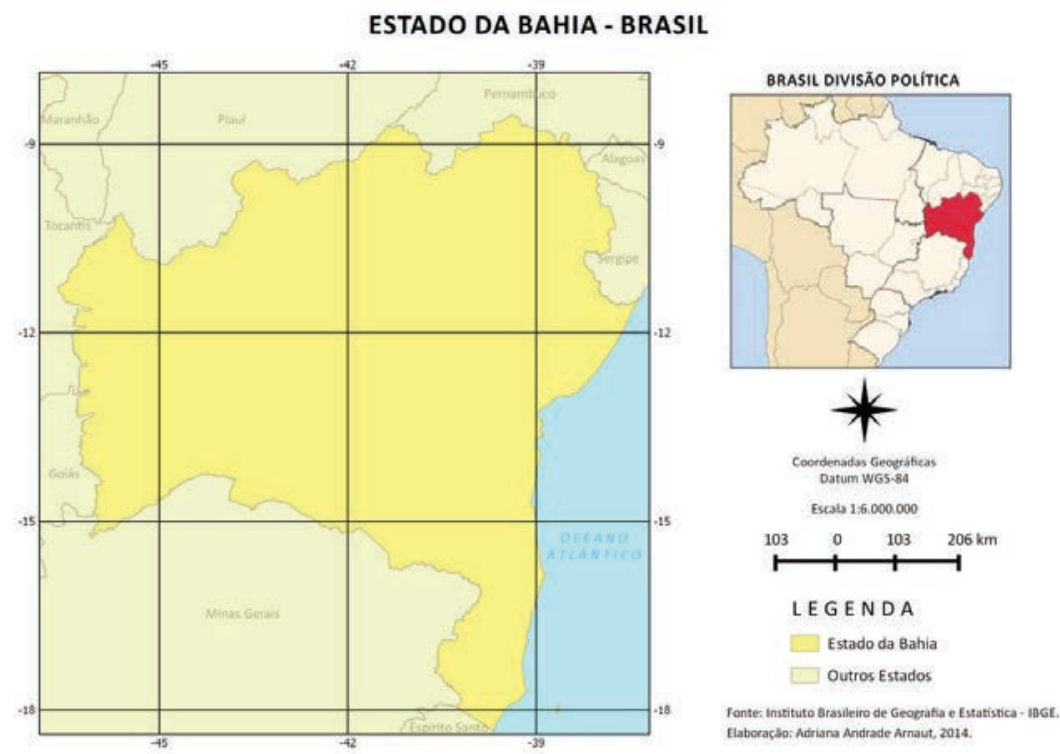

Figura 1 - Mapa de localização do estado da Bahia

Para a elaboração e construção deste trabalho foram realizados os seguintes procedimentos: 1) Coleta dos pontos de focos de calor imageados pelo satélite NOAA-15 (manhã e noite), entre os anos de 2010 e 2013, disponíveis no Programa de Monitoramento de Queimadas e Incêndios do sítio do Instituto Nacional de Pesquisas Espaciais (INPE), em formato shapefile. A base cartográfica digital do estado da Bahia contendo as mesorregiões foi obtida no sítio do IBGE e os dados dos biomas existentes no território baiano foram oriundos do sítio do Ministério do Meio Ambiente (MMA), ambos os dados foram adquiridos no formato shapefile; 2) Dados de precipitação total em milímetros $(\mathrm{mm})$, medidos mensalmente nos anos de 2010 até 2013, através de pluviômetros (estações) distribuídos ao longo do território baiano, e disponibilizados no Banco de Dados Meteorológicos para Ensino e Pesquisa (BDMEP) no sítio do 
Instituto Nacional de Meteorologia (INMET). Utilizando o Microsoft Excel na versão 2007 foi realizada a soma dos valores de precipitação mensal por estação para cada ano e calculada a precipitação média anual para cada mesorregião do estado da Bahia, através da média aritmética; 3) Após a sistematização dos dados coletados, procedeu-se a quantificação dos dados e a elaboração dos mapas dos focos de queimadas utilizando o software Quantum GIS (QGIS) na versão 2.0.1 (Dufour). No QGIS trabalhou-se com a opção unir atributos por localização para cruzar a camada das mesorregiões com as camadas dos pontos de focos de calor dos anos estudados. Neste procedimento foi realizada a contagem/ quantificação dos focos de calor para cada mesorregião. Para a geração do gráfico da contagem de focos de queimadas por ano bem como da precipitação média anual por mesorregião, utilizou-se o Microsoft Excel .

\section{APRESENTAÇÃo DOS RESULTAdos}

No estado da Bahia foram registrados cerca de 28322 casos de focos de queimadas entre os anos de 2010 e 2013. Estes índices podem ser visualizados na Tabela 1, onde no ano de 2010 apresenta o maior percentual $(41,17 \%)$ de focos de queimadas dos últimos 4 anos. A partir de 2011 ocorreu uma diminuição deste percentual (23,26\%), voltando a sofrer um ligeiro aumento em 2012 (28,23\%). Já em 2013, o percentual dos focos de queimadas reduz ao menor valor, o de $7,34 \%$.

Tabela 1 - Quantitativo de focos de queimadas no estado da Bahia entre os anos de 2010 e 2013

\begin{tabular}{|c|c|c|}
\hline Ano & $\mathbf{N}^{\mathbf{0}}$ de Focos & $\%$ \\
\hline 2010 & 11660 & 41,17 \\
\hline 2011 & 6588 & 23,26 \\
\hline 2012 & 7995 & 28,23 \\
\hline 2013 & 2079 & 7,34 \\
\hline$\Sigma$ & $\mathbf{2 8 3 2 2}$ & $\mathbf{1 0 0}$ \\
\hline
\end{tabular}

As Figuras 2, 3, 4 e 5 apresentam os mapas contendo a espacialização dos focos de queimadas no estado da Bahia nos anos de 2010, 2011, 2012 e 2013, respectivamente. 


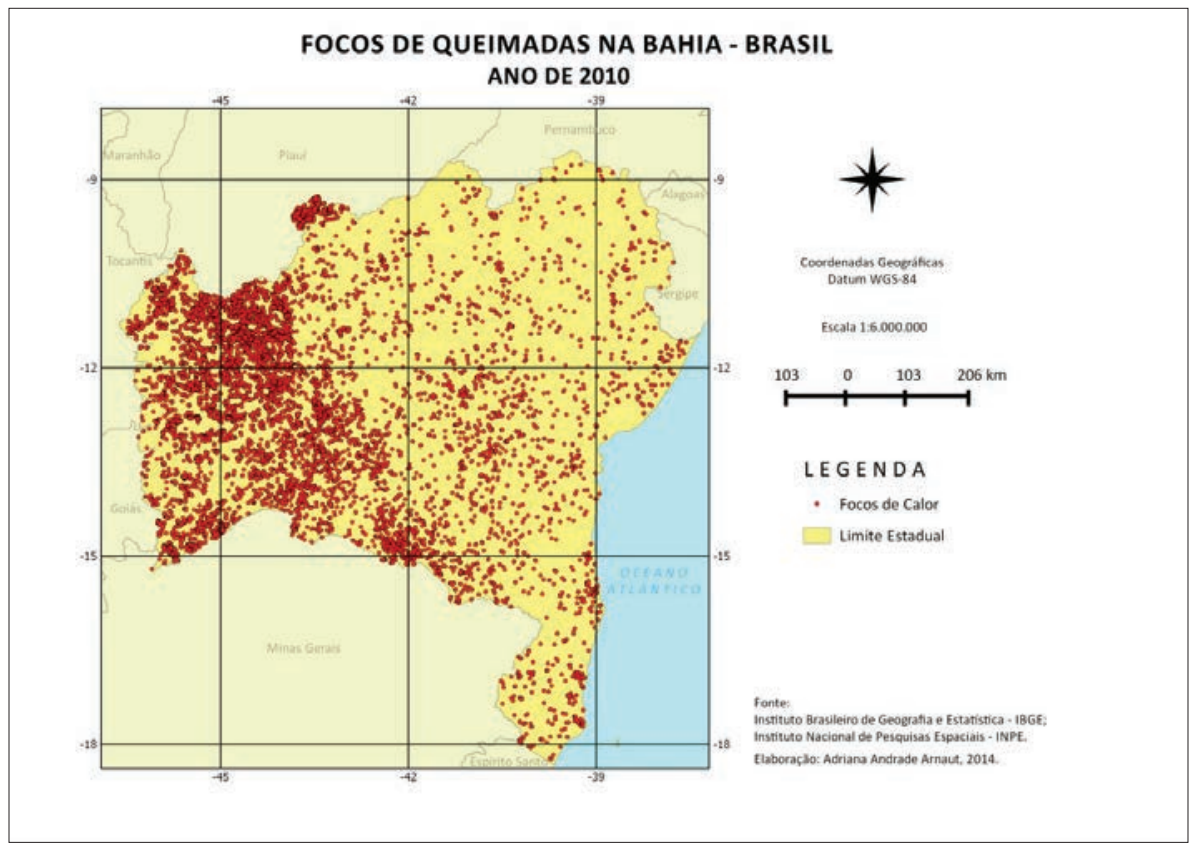

Figura 2 - Espacialização dos focos de queimadas no estado da Bahia no ano de 2010

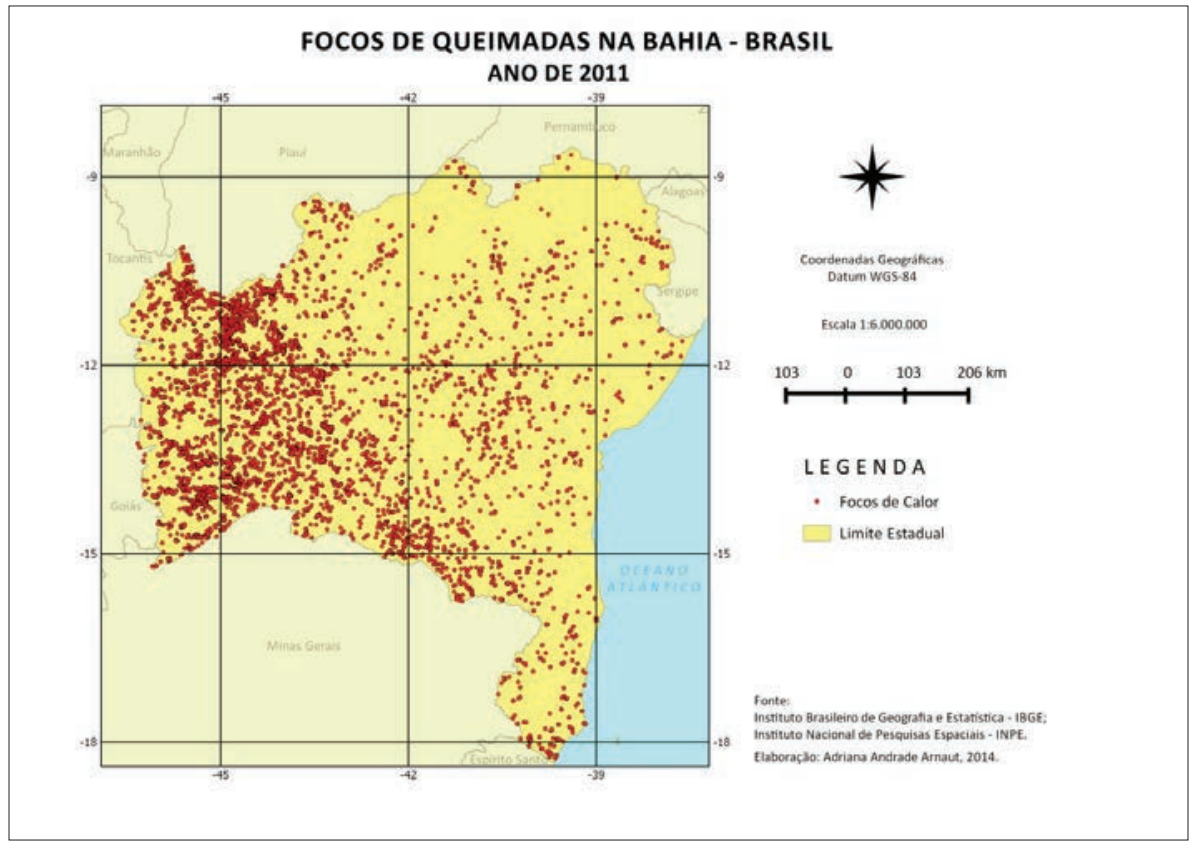

Figura 3 - Espacialização dos focos de queimadas no estado da Bahia no ano de 2011 


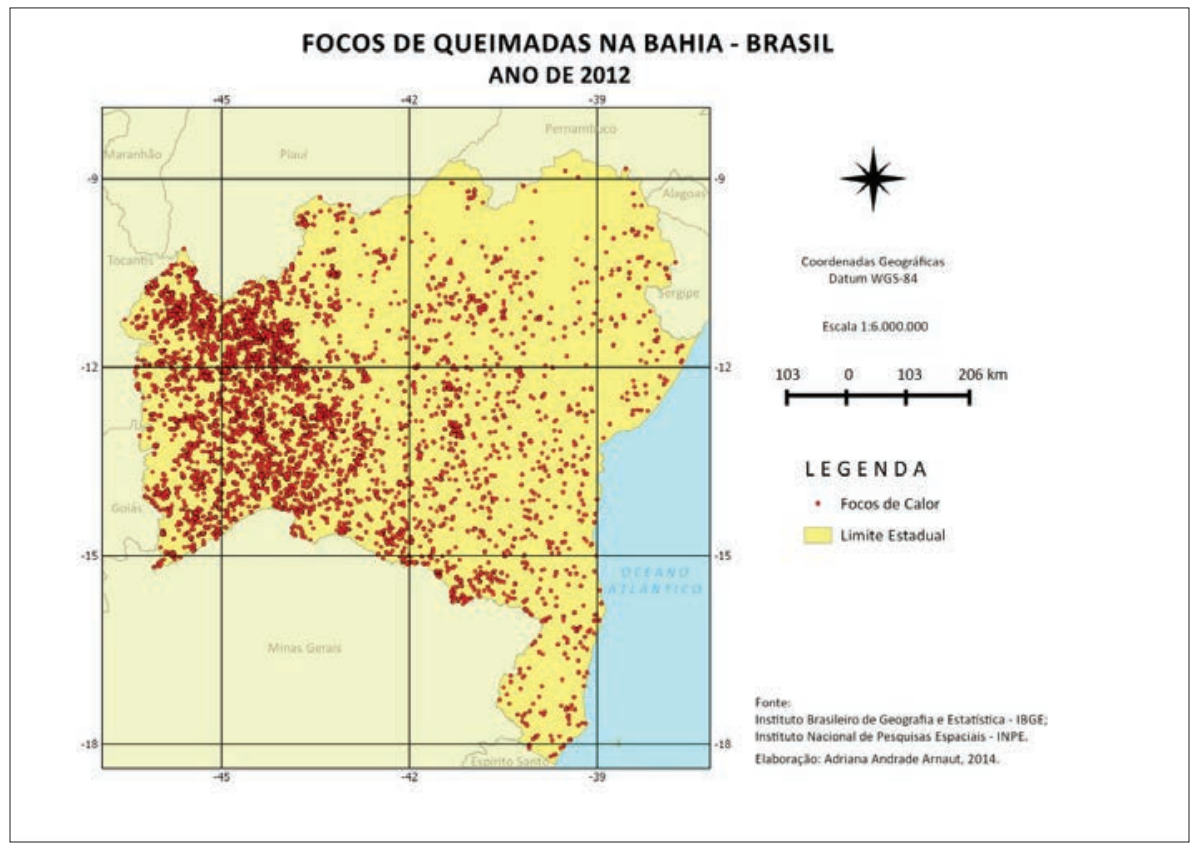

Figura 4 - Espacialização dos focos de queimadas no estado da Bahia no ano de 2012

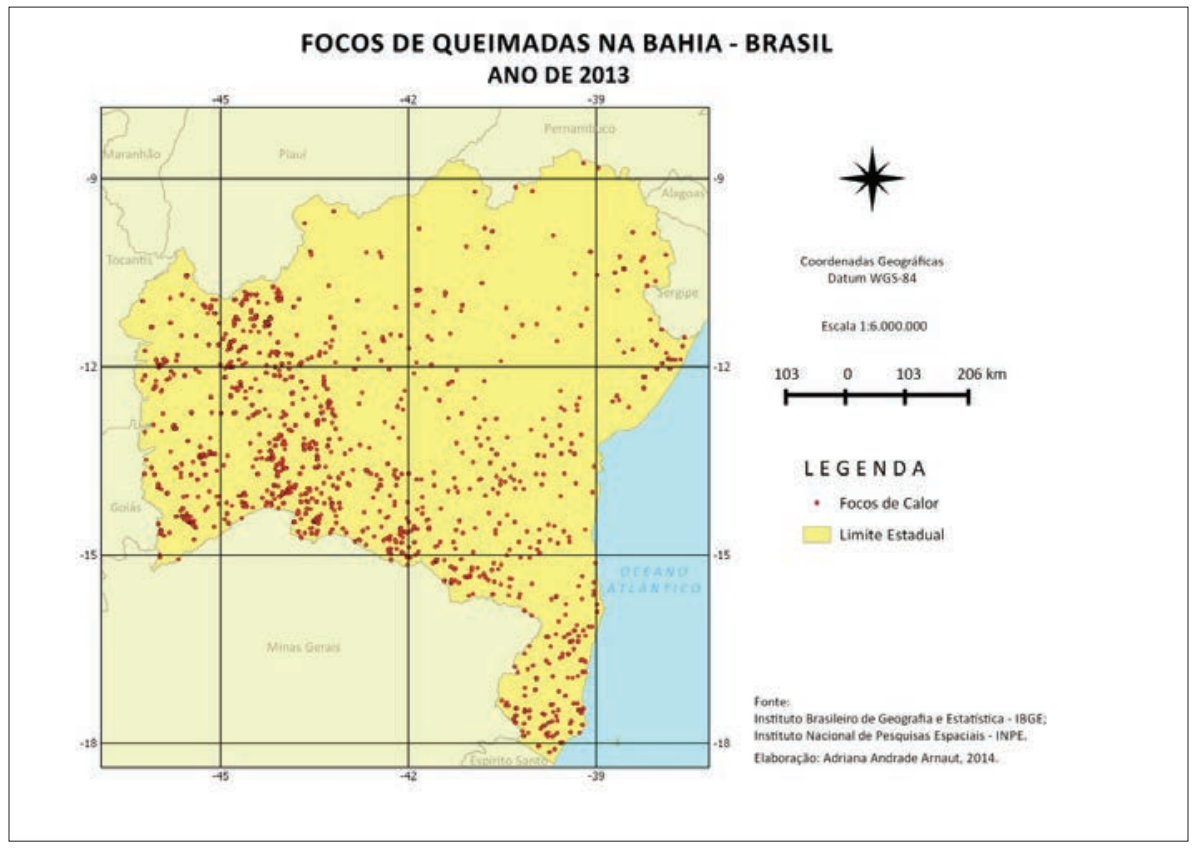

Figura 5 - Espacialização dos focos de queimadas no estado da Bahia no ano de 2013 
A partir dos resultados apresentados anteriormente, gerou-se o gráfico I com a contagem dos focos de queimadas distribuídos nas mesorregiões divididas pelo IBGE que compõem o estado da Bahia, ao longo dos anos pesquisados.

Gráfico I - Contagem dos focos de queimadas no estado da Bahia entre os anos de 2010 e 2013

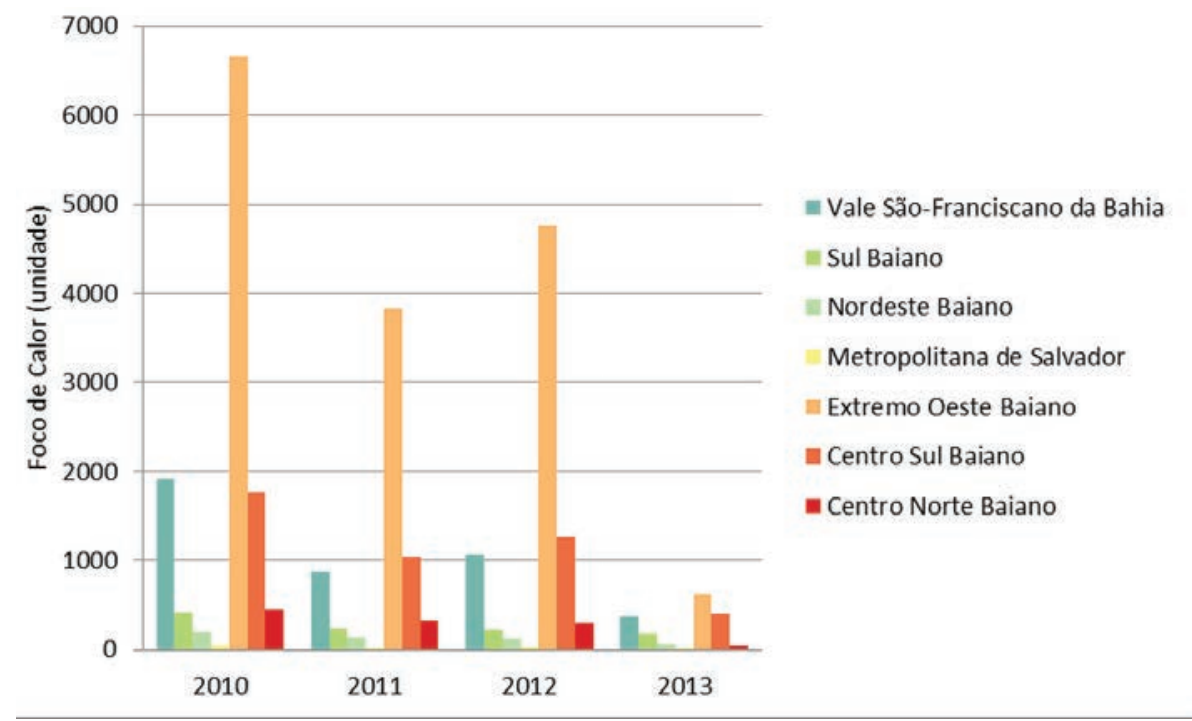

Após a geração do gráfico I, procurou-se verificar em qual bioma (Figura 6) os focos de queimadas se apresentavam em maior quantidade. Em 2010, ocorreu no bioma cerrado, assim como nos demais anos.

Em seguida, com os dados de precipitação do INMET, elaborou-se o gráfico II contendo as precipitações médias anuais das mesorregiões do estado da Bahia para os anos de 2010 até 2013.

A Tabela 2 indica o quantitativo dos focos ativos por estado extraídos das estatísticas do sítio do INPE. 
BIOMAS NAS MESORREGIÕES DA BAHIA - BRASIL
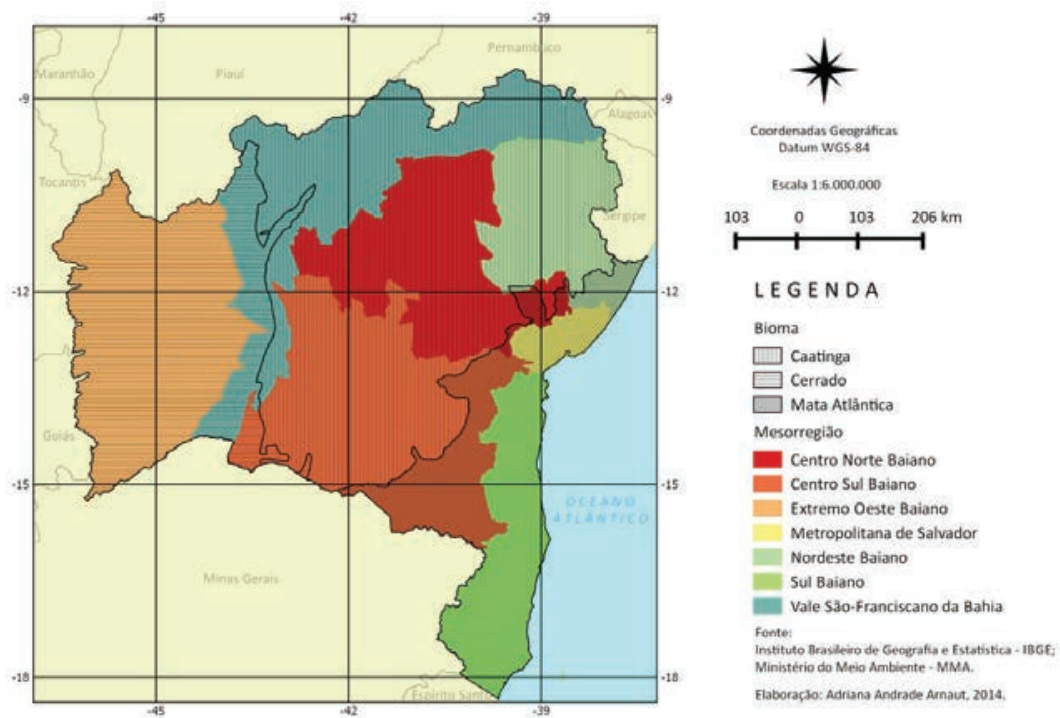

Figura 6 - Biomas nas mesorregiões do estado da Bahia - Brasil

Gráfico II - Precipitação média anual das mesorregiões do estado da Bahia entre os anos de 2010 e 2013

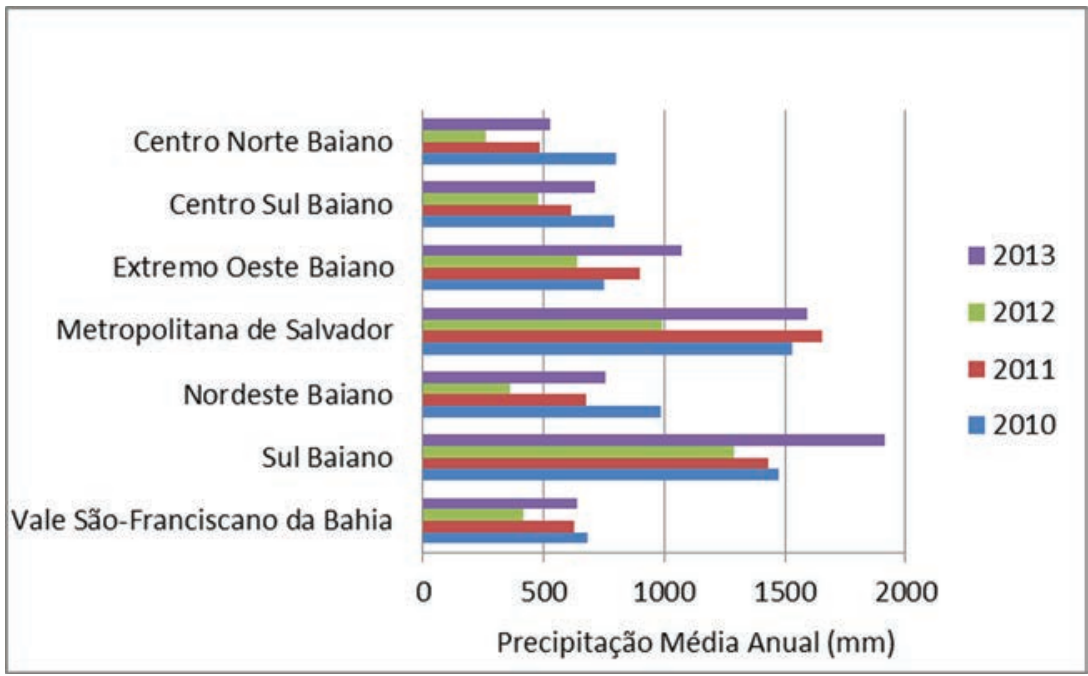


Tabela 2 - Monitoramento dos focos ativos por estado

\begin{tabular}{|c|c|c|c|c|}
\hline \multirow{2}{*}{ Estado } & \multicolumn{4}{|c|}{ Ano } \\
\hline & 2010 & 2011 & 2012 & 2013 \\
\hline Acre (AC) & 4684 & 1912 & 3180 & 3242 \\
\hline Alagoas (AL) & 222 & 232 & 352 & 208 \\
\hline Amapá (AP) & 721 & 1100 & 2103 & 975 \\
\hline Amazonas (AM) & 8826 & 4188 & 7745 & 5118 \\
\hline Bahia (BA) & 15512 & 13061 & 17378 & 7313 \\
\hline Ceará (CE) & 3738 & 3773 & 4040 & 2898 \\
\hline Distrito Federal (DF) & 505 & 273 & 173 & 102 \\
\hline Espírito Santo (ES) & 225 & 326 & 352 & 261 \\
\hline Goiás (GO) & 11104 & 5677 & 6154 & 3002 \\
\hline Maranhão (MA) & 28896 & 14955 & 31594 & 16191 \\
\hline Mato Grosso (MT) & 46936 & 15970 & 26017 & 17823 \\
\hline Mato Grosso do Sul (MS) & 5715 & 3607 & 7546 & 3565 \\
\hline Minas Gerais (MG) & 12166 & 11683 & 10061 & 5382 \\
\hline Pará (PA) & 41066 & 17687 & 26915 & 20542 \\
\hline Paraíba (PB) & 811 & 837 & 525 & 322 \\
\hline Paraná (PR) & 1900 & 2443 & 1760 & 1905 \\
\hline Pernambuco (PE) & 1660 & 1589 & 1089 & 729 \\
\hline Piauí (PI) & 17455 & 10515 & 14604 & 6561 \\
\hline Rio de Janeiro (RJ) & 911 & 1133 & 575 & 405 \\
\hline $\begin{array}{l}\text { Rio Grande do } \\
\text { Norte (RN) }\end{array}$ & 536 & 401 & 395 & 268 \\
\hline Rio Grande do Sul (RS) & 990 & 1033 & 1249 & 944 \\
\hline Rondônia (RO) & 11873 & 4541 & 6421 & 3662 \\
\hline Roraima (RR) & 1442 & 1082 & 1001 & 994 \\
\hline Santa Catarina (SC) & 974 & 926 & 1000 & 1046 \\
\hline São Paulo (SP) & 5194 & 3573 & 2159 & 2055 \\
\hline Sergipe (SE) & 143 & 173 & 231 & 185 \\
\hline Tocantins (TO) & 25069 & 10387 & 19172 & 9786 \\
\hline
\end{tabular}

Fonte: Adaptada de http://www.inpe.br/queimadas/estatisticas_estados.php

\section{DISCUSSÃo DOS RESULTADOS}

Nos últimos quatro anos, a Bahia está inserida entre as seis primeiras colocações do ranking dos estados com maiores focos de queimadas no Brasil. Através da análise do gráfico I, constatou-se que a mesorregião do Extremo Oeste Baiano apresentou as maiores contagens de focos 
de queimadas no decorrer dos anos de 2010 até 2013. Trata-se de uma mesorregião na qual a economia é movimentada pela intensa produção agrícola de cultivo de grãos e pela pecuária, com predomínio do bioma cerrado. Observa-se também pelo gráfico que as mesorregiões seguintes com maior ocorrência de focos no estado foram a do Vale São-Franciscano da Bahia e do Centro Sul Baiano. A primeira localizada no denominado polígono da seca que, segundo o Ministério da Integração Nacional (2005, 3), são regiões com "[...] precipitação pluviométrica média anual inferior a 800 milímetros; índice de aridez de até 0,5 calculado pelo balanço hídrico que relaciona as precipitações e a evapotranspiração potencial, no período entre 1961 e 1990; e risco de seca maior que 60\%, tomando-se por base o período entre 1970 e 1990.” Já a segunda mesorregião tem predominância no bioma de caatinga com clima variando do semiárido a subúmido. Ambas as mesorregiões são também consideradas como de potenciais agrícolas e pecuária. Nos mapas ilustrados nas Figuras 2, 3, 4 e 5 verifica-se a existência de diferentes padrões na espacialização dos focos de calor, mais evidentes nas mesorregiões do Extremo Oeste Baiano, Centro Sul Baiano e Vale São-Franciscano da Bahia. Analisando os dados de chuva para as mesorregiões em estudo apresentados no gráfico II, observa-se que no Extremo Oeste Baiano houve uma precipitação média abaixo de $800 \mathrm{~mm}$ anuais em 2010 e 2012, chegando a $900 \mathrm{~mm}$ em 2011 e ultrapassando os $1000 \mathrm{~mm}$ no ano de 2013. Já na mesorregião do Vale São-Franciscano e Centro Sul Baiano a precipitação média para os anos em estudo não ultrapassou $795 \mathrm{~mm}$, apresentando os piores resultados no ano de 2012 quando não ultrapassou $500 \mathrm{~mm}$ de chuva. Conforme dados divulgados nos boletins sobre a conjuntura econômica da Bahia, disponibilizados pela Superintendência de Estudos Econômicos e Sociais da Bahia (SEI), houve aumento na produção agrícola de grãos no estado da Bahia entre os anos de 2010 a 2013. A produção de grãos é significativa nas regiões em análise e, como já mencionado, pode ser considerado um dos indícios ou agravantes dos focos de queimadas nas mesorregiões. 


\section{CONCLUSÃo}

Com base nos resultados obtidos, pode-se concluir que a geração de mapas com a distribuição temporal e espacial dos focos de calor utilizando a tecnologia de SIG, constitui-se num recurso importante para identificação da localização e adensamento dos focos de queimada no estado da Bahia. Através da contagem dos focos de calor, pôde-se verificar uma acentuada redução dos índices entre os anos de 2010 e 2013. Além disto, constatou-se que a mesorregião Extremo Oeste Baiano, com predomínio do bioma cerrado, apresentou os maiores valores na contagem de focos de calor durante os quatro anos estudados. Estes focos podem estar diretamente relacionados à precipitação média anual na mesorregião e/ou ao uso do solo para fins de expansão agrícola.

\section{BIBLIOGRAFIA}

BURROUGH, Peter A. \& MCDONNELL, Rachael A. (1998) - Principles of Geographical Information Systems. $2^{\text {nd }}$ ed., Oxford University Press, Oxford, 352 p.

CÂMARA, Gilberto \& MEDEIROS, José Simeão de (1998) - Geoprocessamento para Projetos Ambientais. Capítulo 1: Introdução ao Geoprocessamento. $2^{\mathrm{a}}$ ed., São José dos Campos, 14 p. Disponível online no endereço url: http:// www.dpi.inpe.br/gilberto/tutoriais/gis_ambiente/1introd.pdf (acedido em 19 Fevereiro, 2013).

BRASIL - Ministério da Integração Nacional (2005) - Nova Delimitação do SemiÁrido Brasileiro. 33 p. Disponível online no endereço url: http://www. mi.gov.br/c/document_library/get_file?uuid=0aa2b9b5-aa4d-4b55-a6e182faf0762763\&groupId=24915 (acedido em 10 Março, 2014).

Instituto Brasileiro de Geografia e Estatística. IBGE - Mapas. Disponível online no endereço url: http://mapas.ibge.gov.br/bases-e-referenciais/bases-cartograficas/malhas-digitais (acedido em 8 Março, 2014).

Instituto Nacional de Meteorologia. INMET - Banco de dados meteorológicos para Ensino e Pesquisa (BDMEP). Disponível online no endereço url: http://www. inmet.gov.br/portal/index.php?r=bdmep/bdmep (acedido em 30 Maio, 2014).

Instituto Nacional de Pesquisas Espaciais. INPE - Monitoramento de Queimadas. Banco de Dados. Disponível online no endereço url: http://www.dpi.inpe. br/proarco/bdqueimadas/ (acedido em 8 Março, 2014).

FLORENZANO, Tereza Gallotti (2007) - Iniciação em Sensoriamento Remoto. Oficina de Textos, $2^{a}$ ed., São Paulo, 101 p. 
MATIAS, Lindon Fonseca (2001) - Sistema de Informações Geográficas (SIG): Teoria e Métodos para Representação do Espaço Geográfico. Tese de Doutorado da Universidade de São Paulo (USP), Faculdade de Filosofia, Letras e Ciências Humanas, Departamento de Geografia, São Paulo, 325 p. Disponível online no endereço url: www.ige.unicamp.br/.../Sistema \%20de\%20Informacoes\%20Lindon.pdf (acedido em 8 Março, 2014).

Ministério do Meio Ambiente. MMA - Download de dados geográficos. Disponível online no endereço url: http://mapas.mma.gov.br/i3geo/datadownload.htm (acedido em 29 Março, 2014).

Superintendência de Estudos Econômicos e Sociais da Bahia. SEI - Boletim de Conjuntura Econômica da Bahia. Fevereiro de 2012. 12 p. Disponível online no endereço url: http://www.sei.ba.gov.br/images/releases_mensais/pdf/ bceb/bceb_fev_2012.pdf (acedido em 30 Maio, 2014).

Superintendência de Estudos Econômicos e Sociais da Bahia. SEI - Boletim de Conjuntura Econômica da Bahia. Julho de 2012. 14 p. Disponível online no endereço url: http://www.sei.ba.gov.br/images/releases_mensais/pdf/ bceb/bceb_jul_2012.pdf (acedido em 30 Maio, 2014).

Superintendência de Estudos Econômicos e Sociais da Bahia. SEI - Boletim de Conjuntura Econômica da Bahia. Fevereiro de 2013. 16 p. Disponível online no endereço url: http://www.sei.ba.gov.br/images/releases_mensais/pdf/ bceb/bceb_fev_2013.pdf (acedido em 30 Maio, 2014). 
Série Documentos

Imprensa da Universidade de Coimbra

Coimbra University Press

2015

- U M

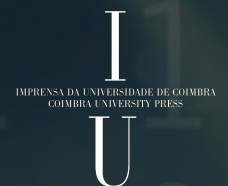

